\title{
A Population of Human Mesenchymal Stem Cells Specific to the Fetal Liver Development
}

Wenwei Zhang ${ }^{1-3}$, Zahia Hamidouche ${ }^{1-3}$, Guillaume Pourcher ${ }^{1-3}$, Varvara Gribova ${ }^{1,2}$, Farhad Haghighi',2, Jean-Jacques Candelier ${ }^{1-3}$, Pierre Charbord $^{1-3}$ and Anne Dubart-Kupperschmitt ${ }^{1-3 *}$

1INSERM UMR_S972, Paul Brousse Hospital, Villejuif, F-94807, France

2Université Paris-Sud, UMR S972, Paul Brousse Hospital, Villejuif, F-94807, France

${ }^{3}$ DHU Hepatinov, Paul Brousse Hospital, Villejuif, F-94807, France

\begin{abstract}
Mesenchymal Stem Cells (MSCs) with osteoblastic/chondrocytic potential have been detected in different anatomical sites including the Fetal Liver (FL). The puzzling presence of such cells in FL led us to investigate whether they displayed additional differentiation competence compatible with their location at this developmental stage. This study has resulted in the successful isolation of a population of clonogenic cells from 11-12 gestational week human fetal livers that spontaneously differentiated into vascular smooth muscle cells during the proliferative phase. The cells were also able to differentiate into adipocytes, osteoblasts and chondrocytes, but only when submitted to specific culture conditions. Moreover, the isolated population expressed hepatocytic transcription factors. The analysis of FL sections suggested that the clones generated in culture were derived from a subset of nestin ${ }^{+}$, vimentin ${ }^{+}$and alpha$\mathrm{SM}$ actin+ pericytes. The FL specification of the MSCs described here is in agreement with the known plasticity of the mesenchyme.
\end{abstract}

Keywords: Differentiation; Vasculature; Bone; Cartilage; Fat; Pericyte; Stromal cell; Hepatocyte; Transcription factor

\section{Introduction}

Mesenchymal Stem Cells (MSCs) are clonogenic cells capable of considerable expansion in culture and, under specific conditions, able to differentiate into the mesenchymal lineages, i.e. osteoblasts, adipocytes and chondrocytes [1]. Because of their mesenchymal differentiation potential and their capacity to express and secrete a number of trophic agents, anti-inflammatory and anti-apoptotic molecules [2,3], this stem cell type has attracted considerable attention and MSCs are presently used in many cell therapy protocols for the treatment of osteo-articular, cardio-vascular and immune diseases [4-7].

MSCs have been isolated firstly from Bone Marrow (BM) aspirates $[8,9]$ and BM remains a major source in many human therapy protocols $[10,11]$. This location is in agreement with the mesenchymal differentiation potential and the capacity of these cells to regenerate bone and cartilage after injury and in case of bone genetic disease [12]. The BM primary localisation of MSCs is also fitting with another major property of these cells, i.e. their capacity to provide stromal cells serving as niches for Hematopoietic Stem Cells (HSCs) by synthesizing factors (cytokines, morphogens, adhesion molecules) essential for HSC self-renewal and commitment into the hematopoietic lineages [13-18]. Due to this niche formation, it is also expected to find MSCs in the other developmental sites of definitive hematopoiesis, such as the fetal liver and aorta-gonads-mesonephros region, and indeed several reports have described cells with mesenchymal differentiation potential and stromal capacity in such sites [19-22]. However, MSCs have also been found in many other tissues unrelated to hematopoiesis, such as adipose tissue, adult liver or pancreas [21,23-25]. This wide distribution has suggested that MSCs are associated to an organismal system and indeed many reports have suggested that MSCs may derive from a population of vascular pericyte-like cells $[20,21,26]$. While this still debated hypothesis may account for the cell distribution, it does not fit with the differentiation potential of the cells, i.e. their capacity to give rise to bone or cartilage in tissues totally devoid of these derivatives, such as the fetal or adult liver.
The purpose of the present study has been to investigate the differentiation potential of MSCs derived from human fetal liver with the underlying assumption that their potential would include nonmesenchymal pathways in agreement with the location of the cells in this site and at this stage. This study has identified clonogenic cells, from 11-12 gestational week (GW) human fetal liver (FL), whose phenotype and differentiation potential are similar to those of BM MSCs. However, we have also demonstrated that these cells differ from bone marrow MSCs by a number of unique features. These differences include their capacity to differentiate into vascular smooth muscle cells (VSMC) during the proliferative phase without addition of specific VSMC inducers, their enhanced proliferation and clonogenic capacity and the expression of specific skeletal muscle and hepatic transcription factors. Anatomo-histological studies suggest that these clonogenic cells are derived from rare nestin + alpha-SM-actin ${ }^{+} /$vimentin $^{+}$vascular cells located in the wall of non-portal vessels. Taken together, our data shows that this cell population represents MSCs specific to the fetal liver development.

\section{Material and Methods}

\section{Fetal liver specimens}

Human fetal livers at GW 11 or 12 were collected and carefully dissected from fetuses after voluntary pregnancy termination with the mothers consent, abiding by the ethical French guidelines.

*Corresponding author: Anne Dubart-Kupperschmitt, INSERM UMR_S972, Paul Brousse Hospital, Villejuif, F-94807, France, Tel: 33145595138; Fax: 33147260319 ; E-mail: anne.dubart@inserm.fr

Received July 31, 2014; Accepted October 20, 2014; Published October 22 2014

Citation: Zhang W, Hamidouche Z, Pourcher G, Gribova V, Haghighi F, et al. (2014) A Population of Human Mesenchymal Stem Cells Specific to the Fetal Liver Development. J Stem Cell Res Ther 4: 238. doi:10.4172/2157-7633.1000238

Copyright: ( 2014 Zhang W, et al. This is an open-access article distributed unde the terms of the Creative Commons Attribution License, which permits unrestricted use, distribution, and reproduction in any medium, provided the original author and source are credited. 


\section{Cell isolation and culture}

Fetal livers were aseptically cut into small pieces and were digested for 1 hour at $37^{\circ} \mathrm{C}$ under gentle stirring in a mixture of collagenases I, III, IV (Sigma C-1639, C-1764, C-1889 respectively, $10 \mathrm{mg} / \mathrm{mL}$ each) and hyaluronidase $10 \mathrm{mg} / \mathrm{mL}$ (Sigma H-3757) in $6 \mathrm{~mL}$ IMDM with $20 \%$ FCS and $1 \mathrm{mM}$ HEPES pH 7.65. The harvested cell suspension was filtered through a $70 \mu \mathrm{m}$ cell strainer then seeded in plating medium (Williams' Medium E/DMEM-F12 (1:1) with 10\% FCS (Hyclone) and $0.1 \%(\mathrm{w} / \mathrm{v}) \mathrm{BSA})$. After 24 hour, the plating medium was replaced by complete medium consisting of a MEM medium with $10 \%$ FCS (Hyclone) and $1 \mathrm{ng} / \mathrm{mL}$ fibroblast growth factor (FGF)-2 (R\&D). The medium was changed every 3-5 days until adherent cells reached confluence. At the first passage, to evaluate the cloning efficiency, cells were seeded by FACS at 1, 2, 5, 10 and 15 cell(s) per well in 96-well plates, not selecting for specific membrane expression. Cells were cultured with complete medium at $37^{\circ} \mathrm{C}, 5 \% \mathrm{CO}_{2}$. The medium was changed every 3-5 days and each clone was individually amplified when cells from wells that were seeded with 1 cell reached confluence.

\section{Statistical data}

Results are given as mean \pm standard error $(\mathrm{m} \pm$ sem). Significance of the difference between groups was evaluated by analysis of variance (ANOVA), followed by a 2 -tailed Student $\mathrm{t}$ test.

Cell differentiation, flow cytometry, Q-RT-PCR, immunofluorescence stainings and Western blotting procedures were performed as previously indicated $[27,28]$. Details are provided in the supplementary material.

\section{Results}

\section{Generation of human FL fibroblastoid clones}

As described in the methods, 22 clones were generated from 11$12 \mathrm{GW}$ human fetal livers from cells that have been selected on their adherence and expansion capacity. The cloning efficiency was 1-4 per 10 seeded cells (Figure 1A, left panel). While some clones developed slowly, showing growth arrest after 15-20 population doublings (PD), faster growing clones propagated for more than $25 \mathrm{PD}$, their division time being approximately 24 hour (Figure 1A, right panel). By day 5 , the cells appeared elongated (Figure 1D, upper panel); by day 14, in confluent cultures, the cells were densely packed but retained contact growth-inhibition (Figure 1D, lower panel). Flow cytometry was used to analyze the expression of cell surface markers of cells from each clone. The results detected the expression of the mesenchymal markers CD73, CD90, CD105, CD146; however there was no expression of the hemato/endothelial markers CD31, CD34 and CD45 (Figure 1B, upper panel). The comparison of the membrane phenotype of the clonal cells with cells from primary layers indicated that some cells from primary layers still expressed CD45 and that the expression of CD90 in these primary layers was heterogeneous (Figure 1B, lower panel). The plot of relative Mean Fluorescence Intensity versus the percentage of positive cells clearly exhibits inter-clonal heterogeneity for CD73, CD90 and CD105 (Figure 1C). The heterogeneity of expression of CD146 was observed for both the clonal cells and the cells from primary layers.

Human FL fibroblastoid clones differentiate into adipocytes $(A)$, osteoblasts $(\mathrm{O})$ and chondrocytes $(\mathrm{C})$ in the presence of specific inducers

To determine whether the clonogenic cells that generated the clonal cells were similar to MSCs, we studied the $\mathrm{A}, \mathrm{O}$, and $\mathrm{C}$ differentiation potential of three healthy well-growing clones generated at passage 1 .
We observed the progressive appearance of Oil red-positive vesicles in clonal cells cultured in adipogenic medium; by day 30 the majority of cells contained these vesicles, which, even at this late stage of culture, remained small-sized (less than $1 \mu \mathrm{m}$ in diameter) (Figure 2Aa, lower panel). Moreover, Q-RT-PCR results indicated the progressive increase of $P P A R G$ expression throughout the culture period, while a transitory increase in $C E B P A$ expression was observed at day 4 (Figure $2 \mathrm{Ab})$. Western blotting revealed a significant $(\mathrm{p}<0.01)$ increase in the expression of peroxisome proliferator-activated receptor gamma (PPARG) and fatty acid-binding protein (FABP4) at day 4 and at day 10 , respectively (Figure 2Ac). In clones grown in osteogenic medium, there was an increase in alkaline phosphatase ${ }^{+}$cells by day 7 , and large areas of mineralization (demonstrated using von Kossa's and alizarin red stains) were apparent by day 21 (Figure 2Ba). We observed through immunostaining, before osteogenic induction, that most cells expressed the runt-related transcription factor 2 protein (RUNX2), the distribution of which was both cytoplasmic and nuclear (Figure $2 \mathrm{Bb}$, left panel). However, 4 days after osteogenic induction, the expression was exclusively nuclear (Figure $2 \mathrm{Bb}$, right panel). Moreover, Q-RTPCR studies indicated a slight but significant $(\mathrm{p}<0.05)$ increase in RUNX2 at day 4 (Figure $2 \mathrm{Bc}$ ). Under chondrogenic conditions, clonal cells developed large aggregates over 3 weeks in culture. By day 21 these aggregates were aggrecan ${ }^{+}$, safranin $\mathrm{O}^{+}$, alcian blue ${ }^{+}$(Figure $2 \mathrm{Ca}$ ) and collagen $\mathrm{II}^{+}$(Figure $2 \mathrm{Cb}$, right panels). Moreover, immunostaining displayed a similar pattern of SOX-9 expression when compared to RUNX2 (Figure 2Cb, left panels).

\section{Human FL MSC clones grown in proliferation medium} differentiate into myogenic cells

We observed through immunostaining that most clonal cells grown in proliferation medium expressed the mesenchymal cytoskeletal markers vimentin and nestin, the vascular smooth muscle cell (VSMC) cytoskeletal marker $\alpha$-smooth muscle (-SM) actin and the myogenic cytoskeletal markers desmin, calponin and $\alpha$-sarcomeric (-SK) actin (Figures 3A and B). The expression of the VSMC cytoskeletal marker SM-myosin was more discrete (Figures $3 \mathrm{~A}$ and $\mathrm{B}$ ). Analysis of protein expression by WB indicated the presence of specific bands for SMmyosin, heavy chain caldesmon, calponin, $\alpha$-SK actin, desmin, $\alpha-S M$ actin, nestin and vimentin and for the myogenic transcription factor myocardin (Figure 3C). Furthermore, the analysis of a number of transcripts affiliated to the skeletal muscle pathway revealed that $P A X 3$ was expressed at levels similar to that of human cultured myoblasts; while MYOD1 expression was also detected at levels 100 times lower than that observed in myoblasts (Figure 3D). These results indicate that the isolated cell population has myogenic differentiation potential.

Human FL MSC clones do not express markers of nonmesenchymal mesoderm nor of pluripotent stem cells

As the FL clonogenic cells exhibited a greater differentiation potential when compared to BM MSCs, we investigated the expression of specific markers characteristic of non-mesenchymal mesodermal blood-forming and endothelial cells. As previously indicated, hematoendothelial cell membrane markers such as CD31 and CD34 were not detected, nor was von Willebrand factor known to be expressed in a granules of endothelial cells and megakaryocytes (not shown). Moreover, hematopoiesis-affiliated transcription factors were not detected, except for RUNX1 (Supplementary Figure 1A).

The expression of the classical markers of pluripotent stem cells was also studied. FACS analysis indicated that MSC clonal cells did not express the pluripotent stem cell marker TRA-1-81 and minimally 


\section{Anne Dubart Kupperschmitt, Fig 1, Top}

A
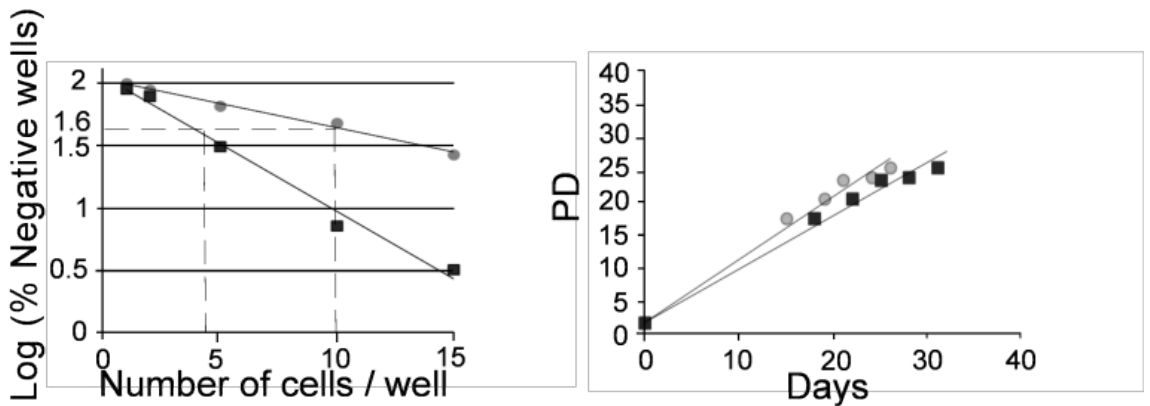

B
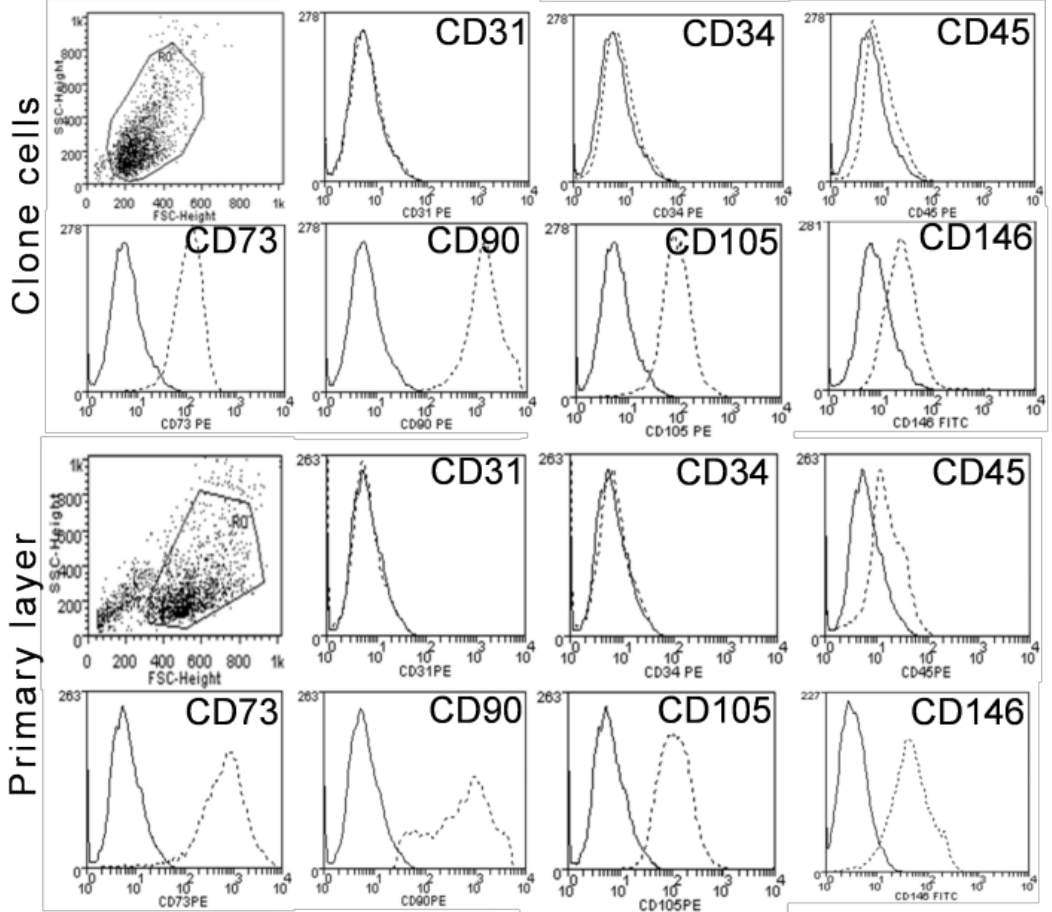

C
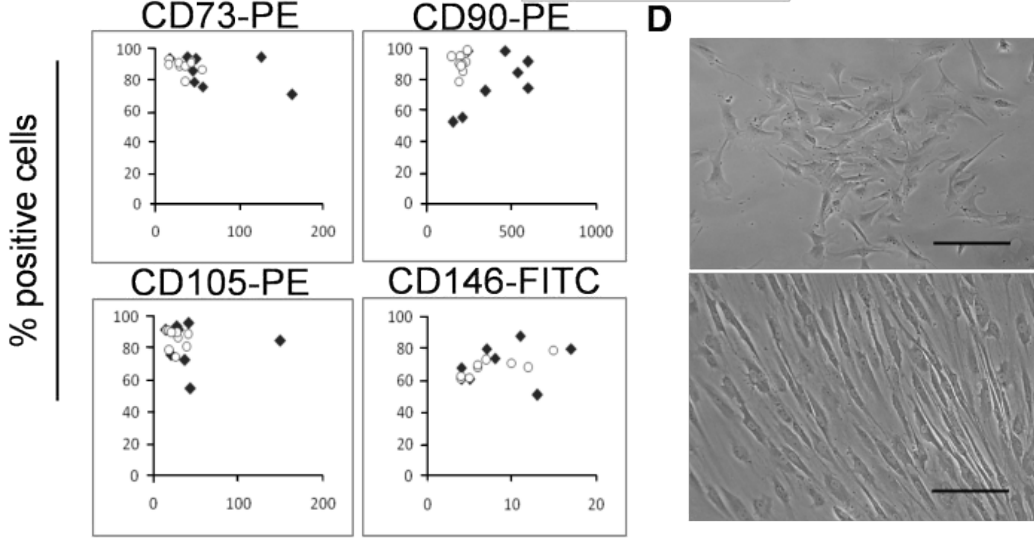

Relative MFI

Figure 1: Clone Generation and Phenotypic Characterization A) Clones generation from primary layers seeded at limiting dilutions when first passaged. Left: Limiting dilution. The cloning efficiency, calculated after verification of the Poisson distribution of the clonogenic cells, was 1 in 4 and 1 in $10\left(r^{2}=0.99\right)$ in the two representative experiments shown. Right: Cumulative population doubling (PD) of two representative clones. Linear adjustment $\left(r^{2}=0.98\right)$. Day 0 indicate the day of limiting dilution corresponding to the first passage of the primary layers. B) Flow cytometry analysis of mesenchymal (CD73, CD90, CD105, CD146), endothelial (CD31, CD34) and hematopoietic (CD45) markers for one representative clone (clone 4 from fetal liver 3: c4FL3) compared to its corresponding primary layer. C) Relative Mean Fluorescence Intensity (MFI) vs. the percentage of positive cells for the different mesenchymal markers. Results for primary layers ( $\mathrm{n}=9$, white circles) and clones ( $n=7$, black diamonds). MFI for each antigen was related to MFI of a corresponding isotype control. D) Phase-contrast microscopy photographs showing the adherent cell morphology of a representative clone (c4FL3). Upper: non confluent culture ( 5 days after seeding); lower: confluent culture (14 days after seeding). Bar: 50 mm. 
Citation: Zhang W, Hamidouche Z, Pourcher G, Gribova V, Haghighi F, et al. (2014) A Population of Human Mesenchymal Stem Cells Specific to the Fetal Liver Development. J Stem Cell Res Ther 4: 238. doi:10.4172/2157-7633.1000238

Aa

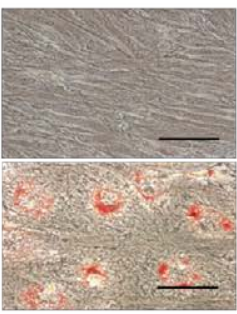

$\mathbf{A b}$

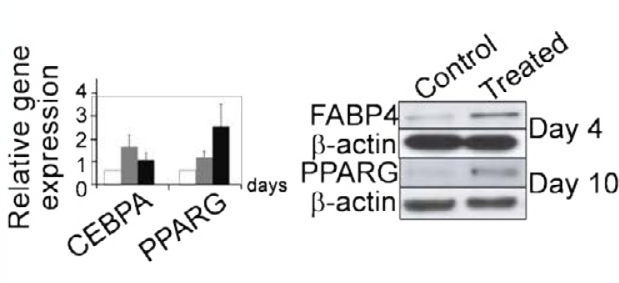

Ac

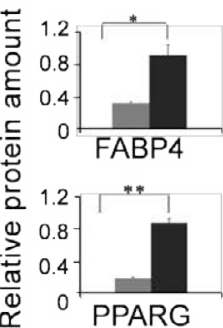

$\mathrm{Ba}$

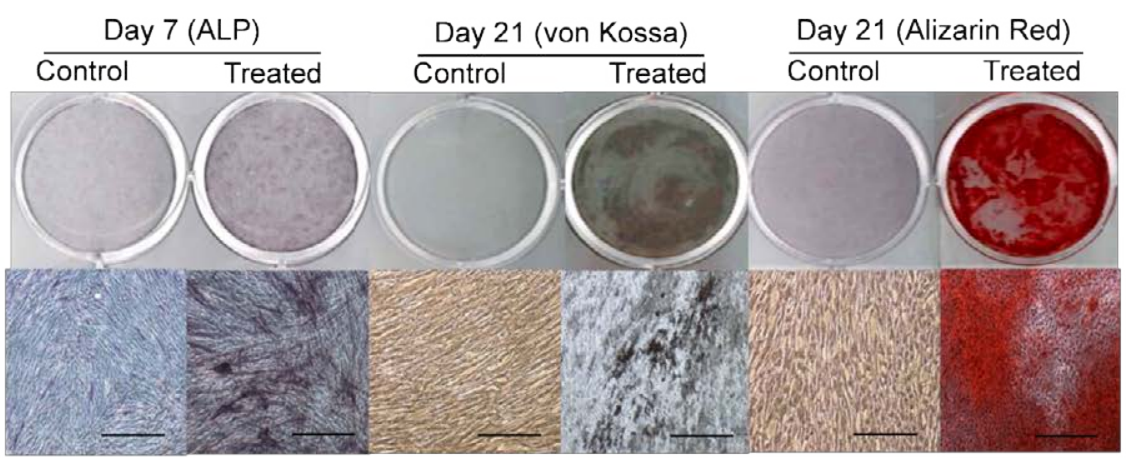

$\mathrm{Bb}$

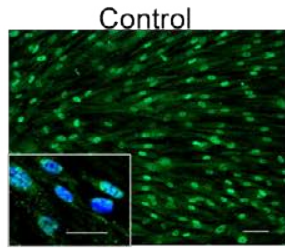

$\mathrm{Ca}$

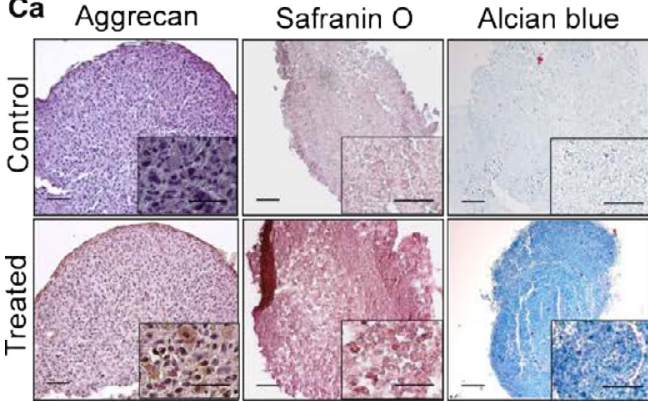

Treated

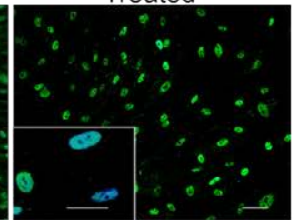

Bc

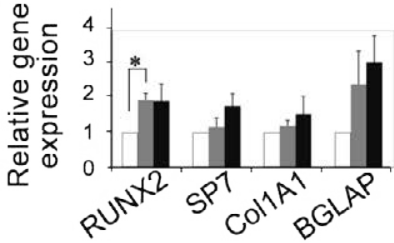

Cb

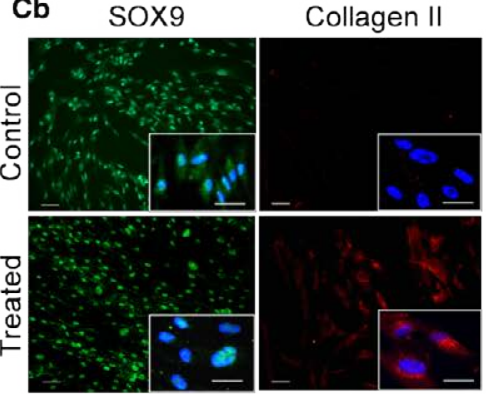

Figure 2: Mesenchymal Differentiation of Clones

A) Adipocytic

a) Morphology of c4FL3 cells stained by Oil Red. Upper: Control culture (untreated) grown in expansion medium for 30 days. Lower: Cells cultured in adipocytic conditions (treated) for 30 days; Bar: $20 \mu \mathrm{m}$

b) Q-RT-PCR data showing the expression of PPARG and CEBPA in 3 clones (c4FL3, c3FL8, c7FL8) at day 4 and day 21 after the induction of differentiation. Values are expressed as mean \pm SEM of gene expression normalized to that of GAPDH and related to that at day 0 ( $\triangle \triangle \mathrm{Ct}$ method). White bars: day 0 ; gray bars: day 4 ; black bars: day 21 . Values at different time-points are not significantly different.

c) Western blot analysis of fatty acid-binding protein 4 (FABP4) and peroxisome proliferator-activated receptor gamma (PPARG) protein levels in clones at day 4 and day 10 after adipocytic induction, respectively. Left: representative western blot (c4FL3). Right: densitometric studies. Mean + SEM of values obtained for clones c4FL3, c3FL8 and c7FL8. Value for each protein was related to that of $\beta$-actin. Gray bars: protein extracts of non-treated cells; black bars: protein extracts of cells 4 or 10 days after adipocytic induction. ${ }^{*} p<0.05,{ }^{* *} p<0.01$.

B) Osteoblastic

a) Histochemistry for clone c4FL3. Left: alkaline phosphatase (ALP) staining showing the initiation of osteoblastic differentiation at day 7 after induction. Centre and Right: mineralization assessed by von Kossa and alizarin stains at day 21. Bars: $50 \mu \mathrm{m}$.

b) Immunofluorescence using antibodies against transcription factor RUNX2 for clone c4FL3 in non-induced (untreated) cells or at day 4 after induction of osteoblastic differentiation (treated). Bars: $10 \mu \mathrm{m}$.

c) Q-RT-PCR data showing expression of RUNX2, SP7, Col1A1 and BGLAP in 3 clones (c4FL3, c3FL8 and c7FL8) at day 4 and day 14 after differentiation induction. Values are expressed as mean \pm SEM of gene expression normalized to that of GAPDH and related to that at day 0 ( $\triangle \triangle \mathrm{Ct}$ method). White bars: day 0 ; gray bars: day 4 ; black bars: day $14 .{ }^{*} p<0.05$.

C. Chondrocytic

a) Aggrecan, safranin $\mathrm{O}$ and alcian blue stainings for clone c4FL3 at day 21 in absence of induction (untreated) or after differentiation induction (treated). For each staining, a magnification view is shown in insert. Bars: $25 \mu \mathrm{m}$.

b) Immunofluorescence for transcription factor SOX9 and for collagen II in the representative clone (c4FL3) in absence of induction (untreated) or at day 7 after differentiation induction (treated). Bars: $10 \mu \mathrm{m}$. 
Anne Dubart Kupperschmitt, Fig 3, Top
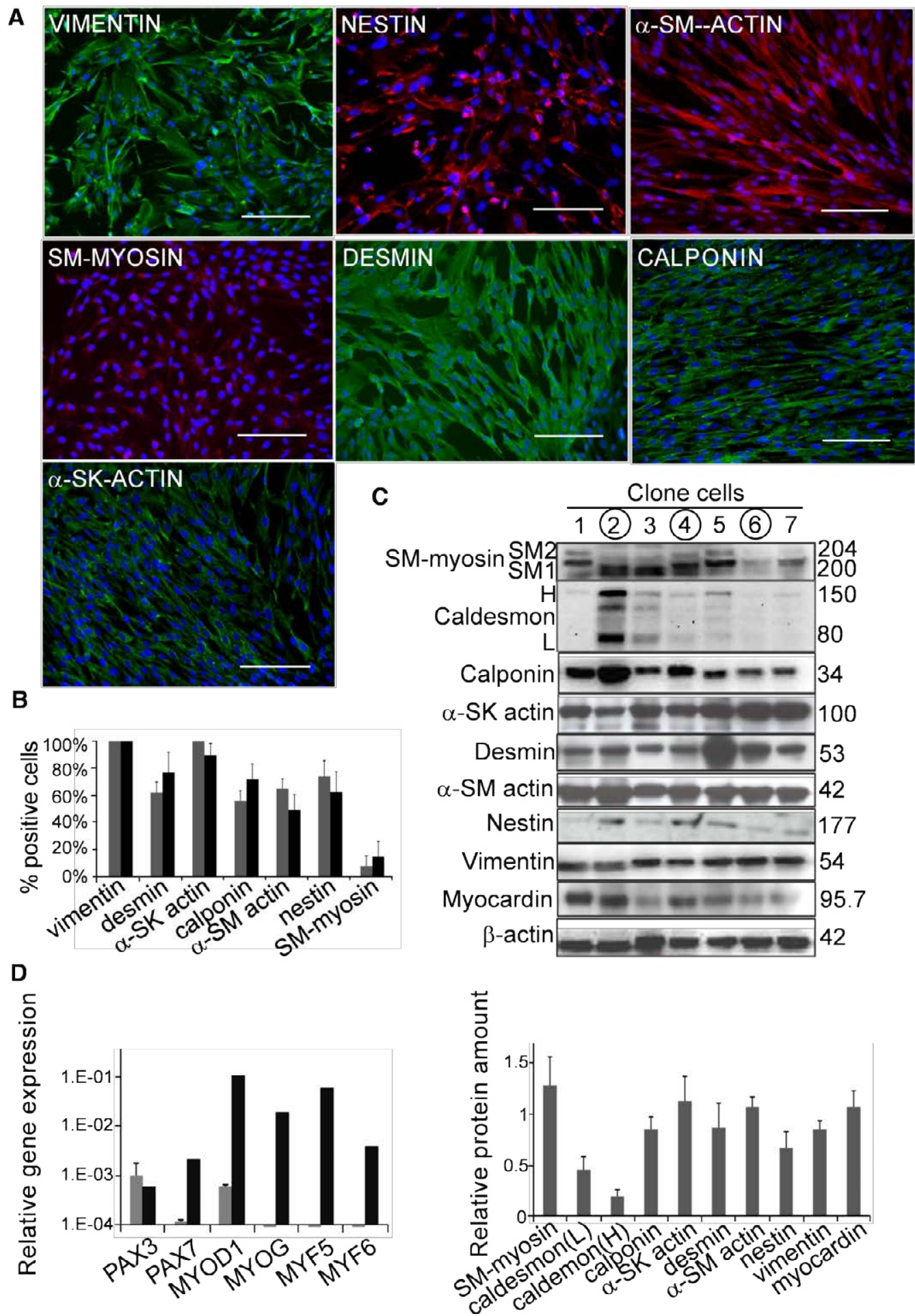

Figure 3: Myogenic Differentiation of Clones A ) Immunofluorescence studies for the representative clone c4FL3 using antibodies against vimentin, nestin, $\alpha$-smooth muscle actin ( $\alpha$-SM-actin), SM-myosin, desmin, calponin and $\alpha$-sarcomeric actin ( $\alpha$-SK-actin). Bars: $25 \mu \mathrm{m}$. B) Percentage of positive cells for the different markers in immunofluorescence studies like those illustrated in A. Values are expressed as mean \pm SEM. Results for primary layers ( $n=9$, gray bars) and clones ( $=7$, black bars). Differences are not significant. C) Western blot analyses. Upper panel: Western blot analyses for SM-myosin, caldesmon, calponin, a-SK actin, desmin, a-SMA, nestin, vimentin and myocardin in 7 clones. Encircled numbers indicate clones c4FL3, c3FL8 and c7FL8. Lower panel: corresponding densitometry data (mean \pm SEM; value for each protein related to that of $\beta$-actin). D) Q-RT-PCR data for transcription factors implicated in skeletal muscle differentiation (PAX3, PAX7 MYOD1, MYOG, MYF5, MYF6) in 3 clones (c4FL3, c3FL8 and c7FL8) and in normal human cultured myoblasts. Values are expressed as mean \pm SEM of gene expression normalized to that of $\mathrm{GAPDH}(\triangle \mathrm{Ct}$ method). Gray bars: clones; Black bars: myoblasts. 
expressed SSEA-4 (Supplementary Figure 1B). Moreover, there was no expression of NANOG and OCT4 proteins, and the marginal transcriptional expression of NANOG, POU5F1 and SOX2 was 2-3 log levels lower when compared to human Embryonic Stem Cells (hESCs), contrasting with the high expression of MYC and KLF4 transcripts (at levels similar to those in hESCs) (Supplementary Figure 1C,D). The MYC proto-oncogene protein was also detected in clonal cells (Supplementary Figure 1D).

\section{Human FL MSC clones express some early hepatic transcription factors but no cytoplasmic markers characteristic of developing hepatocytes}

MSCs have been shown to exhibit specific features related to the tissue they were initially isolated from. Therefore, we assessed characteristics related to the hepatic origin of the MSC clones. Among the transcription factors implicated in hepatic differentiation and development we detected marginal expression of the HNF1 $\alpha$ and FOXA2 transcripts while $H N F 1 \beta$ was expressed at a level similar to that of the HuH7 human hepatocarcinoma cell line (Figure 4Aa). The Hepatocyte nuclear factor (HNF) $1 \alpha, 1 \beta$ and $3 \beta$ proteins were expressed primarily in the nucleus with a scattered pattern for HNF3 $\beta$ that was not discerned in the nuclei of the $\mathrm{HuH} 7$ cell line (Figure $4 \mathrm{Ab})$. In addition, $\alpha$-fetoprotein and albumin, which are expressed in the cytoplasm of developing hepatocytes, were not detected. We also showed the high expression of the mRNAs encoding SNAI1, SNAI2 and TWIST transcription factors known to regulate the mesenchymalto-epithelial transition (Figure 4Ac) [29].

\section{Clonogenic cells appears to derive from a population of fetal liver pericytic-like vascular cells}

Paraffin embedded fetal liver sections were stained with a panel of antibodies directed at antigens specific for the various liver cell populations. As expected, hepatoblasts were uniformly positive for E-cadherin and cytokeratin 18, while biliary cells and Kupffer cells were positive for cytokeratin 19 and CD68, respectively (Supplementary Figure 2). Rare cells on the abluminal side of the endothelium lining large sinusoids and centro-lobular sinuses expressed $\alpha$-SM actin, nestin and vimentin, but did not express CD34 (Figure 4B). These cells were therefore clearly distinct through their morphology, location and phenotype from endothelial cells.

\section{Discussion}

Here we describe a population of 11-12 GW human fetal liver clonogenic cells that give rise in culture to myogenic cells with mesenchymal (osteoblastic, adipocytic and chondrocytic) potential. These cells appear to be derived from a population of fetal liver mural vascular cells selected by their adherent properties and expanded, under our culture conditions, at the expense of the other liver cell types.

Although the clonogenic cells we developed gave rise in culture to cells expressing the usual human BM MSC membrane markers [1,3032] and could be induced to differentiate into the usual mesenchymal lineages, they differed from BM MSCs by a number of characteristics. Firstly, the cloning efficiency was superior in FL MSCs compared to BM MSCs. In particular, the FL clones could be generated from primary layers at passage 1 whereas BM MSC clones could, in our experience, only be derived at culture inception [28]. Secondly, the heterogeneity of CD146 expression did not predict the differentiation potential of the FL MSCs contrary to what has been described for BM MSCs [33]. Thirdly, in order to stimulate the adipocytic differentiation potential of the clonal cells, the adipogenic cocktail had to be enriched by adding rosiglitasone and insulin to dexamethasone, IBMX and indomethacin. Moreover, despite the modified conditions, adipogenesis was delayed by more than 10 days when compared to BM cells. These results suggest that the activation of multiple signaling pathways in fetal cells is required to achieve adipogenic differentiation. Fourthly, in expansion medium not supplemented with specific vasculogenic inducers, the clonogenic cells differentiated into vascular smooth muscle cells expressing specific skeletal muscle transcription factors. The latter observation indicates that, in contrast to trilineal BM MSCs [28], FL MSCs are quadripotential, displaying both mesenchymal and myogenic differentiation potential. Moreover, the default differentiation pathway of the FL MSCs appears to be vasculogenic, whereas in BM MSCs it is osteogenic [34]. An additional difference between BM and FL MSCs was the expression of different markers characteristic of the hepatocytic lineage in FL MSCs. We identified the expression, both at the mRNA and protein level, of the transcription factors FOXA2 and HNF1 $\beta$ known to be critical for the proper commitment to and differentiation into the hepatocytic lineage during development [35,36]. However, no other hepatic-specific cytoplasmic markers such as albumin or alpha-feto protein normally expressed at later stages of hepatocyte differentiation were detected. Moreover, we observed the expression of transcripts such as the zinc finger transcription factor SNAI1 known to critically impede the mesenchymal-to-epithelial transition [29]. The simultaneous expression of transcription factors either favoring or hampering the differentiation into hepatocytes suggests that these cells may be in a poised state in which the genes required for hepatocytic differentiation are repressed. Further studies are required to demonstrate that the promoters of the marginally expressed hepatic transcription factors are associated to chromatin in bivalent state and to show that, in the presence of chromatin remodelers specific growth factors and extra-cellular matrices, these cells are able to differentiate into bipotential (hepatocytic and biliary) hepatic progenitors.

The use of fetal cells for cell therapy in humans cannot be envisioned unless to provide proof of concept in very particular circumstances, as exemplified for Parkinson's disease [37]. However, lessons might be taken from the study of fetal cells. In the present case, we show that cells akin to BM MSCs may acquire, at a distinct developmental stage and precise anatomical location, some features characteristic of hepatocytes. This suggests that it may be relatively easy to reprogram BM MSCs into hepatocytes by providing factors (cytokines, morphogens and adhesion molecules) present in the fetal liver microenvironment. Future studies have to be devised following this approach since new sources of cells are absolutely needed for transplantation in patients with liver insufficiency [38].

In conclusion, the cells described here appear to correspond to MSCs according to their phenotype, proliferative capacity and their differentiation potential to the mesenchymal lineages. However, they differ from BM MSCs in other differentiation patterns, mainly their capacity to differentiate into mural vascular cells (akin to smooth muscle cells or pericytes) and to express some master hepatogenic transcription factors. The vascular mural origin and differentiation potential is in agreement with the cell location at this stage when the vascular system organizing the hepatic trabeculae undergoes major extension. The expression of hepatocytic markers suggests that these cells may also contribute to the hepatic cord, which has to be further substantiated. The acquisition by cells collectively described as "MSCs" of properties specific to their location and developmental stage is related to the known plasticity of the mesenchyme, i.e. its capacity to modulate its properties according to external conditions $[28,39,40]$. This plasticity may explain the activation, in the fetal liver cells 
Citation: Zhang W, Hamidouche Z, Pourcher G, Gribova V, Haghighi F, et al. (2014) A Population of Human Mesenchymal Stem Cells Specific to the Fetal Liver Development. J Stem Cell Res Ther 4: 238. doi:10.4172/2157-7633.1000238

1 a

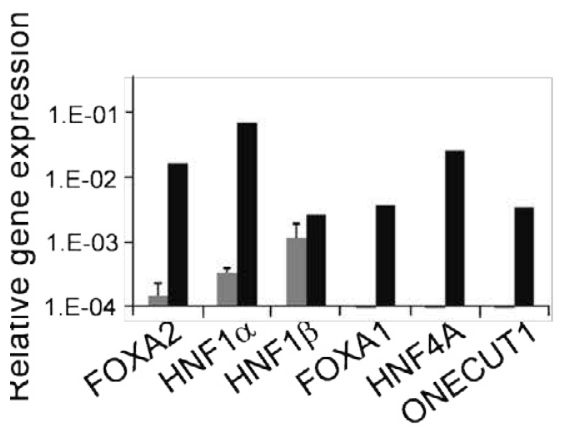

tb MSC clone cells
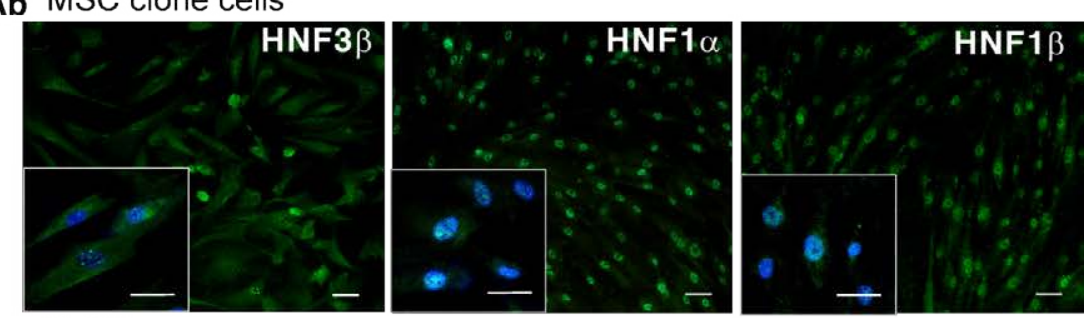

\section{$\mathrm{HuH7}$}
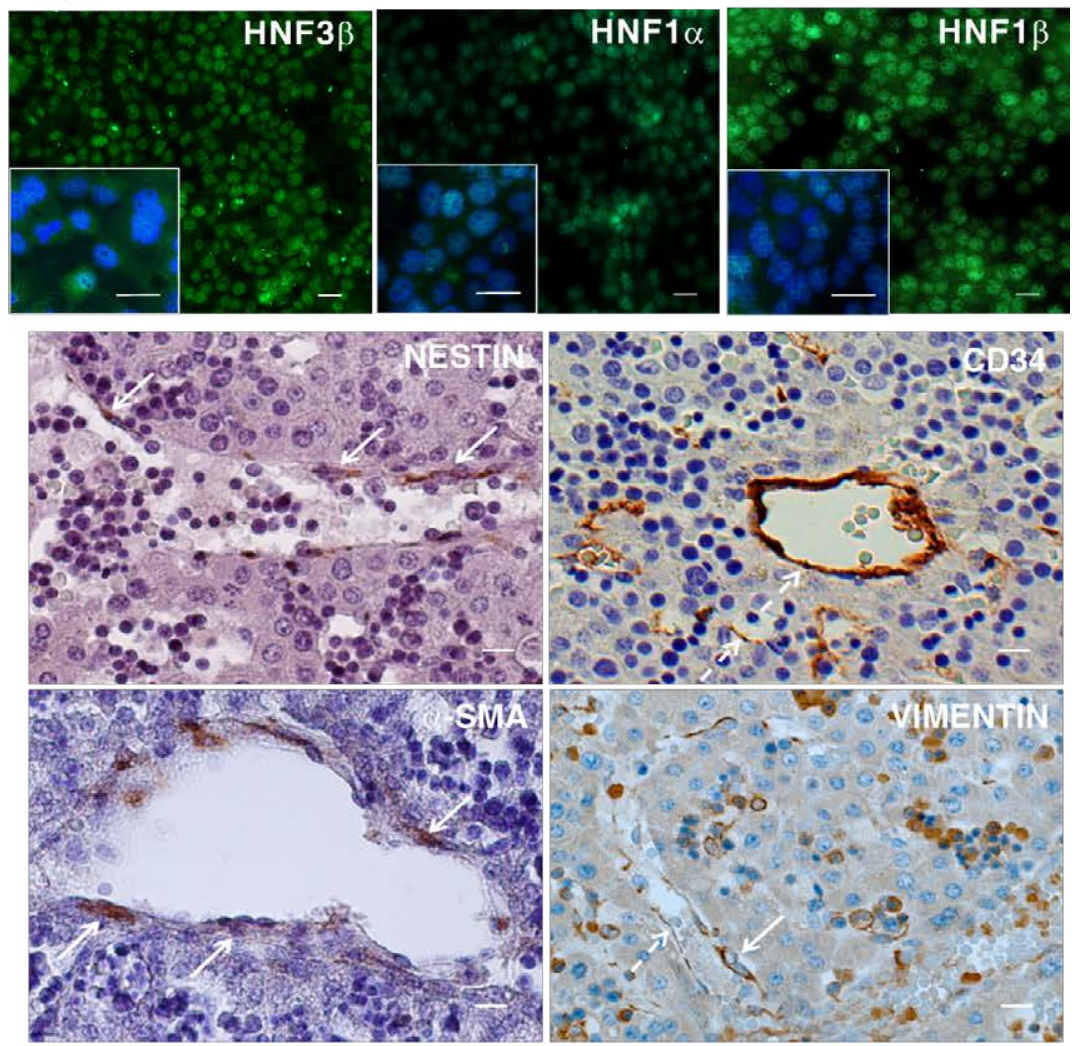

Figure 4: Analysis of the hepatocytic differentiation pathway and anatomical study

A) Hepatocytic differentiation pathway

a) Q-RT-PCR data for hepatic nuclear transcription factors in 3 clones (c4FL3, c3FL8 and c7FL8). Values are expressed as mean \pm SEM of gene expression normalized to that of GAPDH ( $\triangle \mathrm{Ct}$ method). Gray bars: clones; Black bars: human hepatocytic HuH7 cell line

b) Immunofluorescence using antibodies against HNF3 $\beta$, HNF1 $\alpha$ and HNF1 $\beta$ proteins. Upper: c7FL8; lower: HuH7, as control. Bars: 10 $\mu m$.

B) Epithelial to mesenchymal transition

Q-RT-PCR data for transcription factors SNAI1, SNAI2 and TWIST implicated in epithelial-to-mesenchymal transition (EMT) in 3 clones (c4FL3, c3FL8 and c7FL8). Values are expressed as mean \pm SEM of gene expression normalized to that of GAPDH ( $\triangle \mathrm{Ct}$ method).

C) Anatomical study

In situ marker localization of the potential cell population of origin of MSCs in human 11-12 GW fetal liver. Immunohistochemistry using antibodies against nestin, CD34, a-SM actin and vimentin. Continuous arrows indicate pericytes; broken arrows indicate endothelial lining. Bars: 10 $\mu \mathrm{m}$. 
Citation: Zhang W, Hamidouche Z, Pourcher G, Gribova V, Haghighi F, et al. (2014) A Population of Human Mesenchymal Stem Cells Specific to the Fetal Liver Development. J Stem Cell Res Ther 4: 238. doi:10.4172/2157-7633.1000238

described here, of genes and pathways less prominent or extinct in the corresponding bone marrow cells.

\section{Acknowledgment}

The authors thank Jean-Thomas Vilquin (INSERM UMRS 974 / CNRS UMR 7215 / UPMC), Anne Weber, Clara Steichen (INSERM UMRS 972/ Univ ParisSud 11) for providing cell samples, cell lineages and hESC pictures, respectively; they are also grateful to Denis Clay for cell sorting, to Olivier Trassard (IFR93, KremlinBicêtre) for imaging expertise, and to Marie-Thérèse Groyer-Picard and Sylvie Goulinet-Mainot for excellent technical support. Finally, the authors are grateful to Zara Hannoun for careful reading and editing of the manuscript. WZ was supported by fellowships from INSERM and Région lle de France (DIM Stem Pôle). ZH was supported by the INCA grant BORTES and a fellowship from NRB. GP was supported by a fellowship from NRB.

\section{References}

1. Pittenger MF, Mackay AM, Beck SC, Jaiswal RK, Douglas R, et al. (1999) Multilineage potential of adult human mesenchymal stem cells. Science 284 : 143-147. [PubMed]

2. Caplan Al, Dennis JE (2006) Mesenchymal stem cells as trophic mediators. Journal of Cellular Biochemistry 98: 1076-1084.

3. Phinney DG, Prockop DJ (2007) Concise review: mesenchymal stem/ multipotent stromal cells: the state of transdifferentiation and modes of tissue repair--current views. Stem Cells 25: 2896-2902. [PubMed]

4. Baron F, Storb R (2012) Mesenchymal stromal cells: a new tool against graftversus-host disease?, Biology of blood and marrow transplantation. Journa of the American Society for Blood and Marrow Transplantation 18: 822-840. [PubMed]

5. Dominguez-Bendala J, Lanzoni G, Inverardi L, Ricordi C (2012) Concise review: mesenchymal stem cells for diabetes. Stem Cells Transl Med 1: 59-63. [PubMed]

6. Singer NG, Caplan Al (2011) Mesenchymal stem cells: mechanisms of inflammation. Annu Rev Pathol 6: 457-478. [PubMed]

7. Tyndall A, Uccelli A (2009) Multipotent mesenchymal stromal cells for autoimmune diseases: teaching new dogs old tricks. Bone Marrow Transplantation 43: 821-828. [PubMed]

8. Caplan Al (1991) Mesenchymal stem cells. J Orthop Res 9: 641-650. [PubMed]

9. Friedenstein AJ, Chailakhjan RK, Lalykina KS (1970) The development of fibroblast colonies in monolayer cultures of guinea-pig bone marrow and spleen cells. Cell and tissue kinetics 3: 393-403. [PubMed]

10. Satija NK, Singh VK, Verma YK, Gupta P, Sharma S, et al. (2009) Mesenchyma stem cell-based therapy: a new paradigm in regenerative medicine. J Cell Mol Med 13: 4385-4402. [PubMed]

11. Vinatier C, Bouffi C, Merceron C, Gordeladze J, Brondello JM, et al. (2009) Cartilage tissue engineering: towards a biomaterial-assisted mesenchymal stem cell therapy. Curr Stem Cell Res Ther 4: 318-329. [PubMed]

12. Horwitz EM, Gordon PL, Koo WK, Marx JC, Neel MD, et al. (2002) Isolated allogeneic bone marrow-derived mesenchymal cells engraft and stimulate growth in children with osteogenesis imperfecta: Implications for cell therapy of bone. Proc Natl Acad Sci U S A 99: 8932-8937. [PubMed]

13. Briquet A, Dubois S, Bekaert S, Dolhet M, Beguin Y, et al. (2010) Prolonged ex vivo culture of human bone marrow mesenchymal stem cells influences their supportive activity toward NOD/SCID-repopulating cells and committed progenitor cells of $B$ lymphoid and myeloid lineages. Haematologica 95: 47-56. [PubMed]

14. Charbord $P$ (2010) Bone marrow mesenchymal stem cells: historical overview and concepts. Hum Gene Ther 21: 1045-1056. [PubMed]

15. Dennis JE, Carbillet JP, Caplan AI, Charbord P (2002) The STRO-1+ marrow cell population is multipotential. Cells Tissues Organs 170: 73-82. [PubMed]

16. Majumdar MK, Thiede MA, Haynesworth SE, Bruder SP, Gerson SL (2000) Human marrow-derived mesenchymal stem cells (MSCs) express hematopoietic cytokines and support long-term hematopoiesis when differentiated toward stromal and osteogenic lineages. Journal of Hematotherapy \& Stem Cell Research 9: 841-848. [PubMed]
17. Prockop DJ (1997) Marrow stromal cells as stem cells for nonhematopoietic tissues. Science 276: 71-74. [PubMed]

18. Wagner W, Roderburg C, Wein F, Diehlmann A, Frankhauser M, et al. (2007) Molecular and secretory profiles of human mesenchymal stromal cells and their abilities to maintain primitive hematopoietic progenitors. Stem Cells 25: 26382647. [PubMed]

19. Campagnoli C, Roberts IA, Kumar S, Bennett PR, Bellantuono I, et al. (2001) Identification of mesenchymal stem/progenitor cells in human first-trimester fetal blood, liver, and bone marrow. Blood 98: 2396-2402. [PubMed]

20. Crisan M, Yap S, Casteilla L, Chen CW, Corselli M, et al. (2008) A perivascula origin for mesenchymal stem cells in multiple human organs. Cell Stem Cell 3 301-313. [PubMed]

21. da Silva Meirelles L, Chagastelles PC, Nardi NB (2006) Mesenchymal stem cells reside in virtually all post-natal organs and tissues. Journal of Cell Science 119: 2204-2213. [PubMed]

22. Wang XY, Lan Y, He WY, Zhang L, Yao HY, et al. (2008) Identification of mesenchymal stem cells in aorta-gonad-mesonephros and yolk sac of human embryos. Blood 111: 2436-2443. [PubMed]

23. Strioga M, Viswanathan S, Darinskas A, Slaby O, Michalek J (2012) Same or not the same? Comparison of adipose tissue-derived versus bone marrowderived mesenchymal stem and stromal cells. Stem Cells Dev 21: 2724-2752. [PubMed]

24. Gimble JM, Katz AJ, Bunnell BA (2007) Adipose-derived stem cells for regenerative medicine. Circulation research 100: 1249-1260. [PubMed]

25. Zuk PA, Zhu M, Ashjian P, De Ugarte DA, Huang Jl, et al. (2002) Human adipose tissue is a source of multipotent stem cells. Mol Biol Cell 13: 42794295. [PubMed]

26. da Silva Meirelles L, Caplan AI, Nardi NB (2008) In search of the in vivo identity of mesenchymal stem cells. Stem Cells 26: 2287-2299. [PubMed]

27. Delorme B, Charbord $P$ (2007) Culture and characterization of human bone marrow mesenchymal stem cells. Methods Mol Med 140: 67-81. [PubMed]

28. Delorme B, Ringe J, Pontikoglou C, Gaillard J, Langonne A, et al. (2009) Specific Lineage-Priming of Bone Marrow Mesenchymal Stem Cells Provides the Molecular Framework for Their Plasticity. Stem Cells 27: 1142-1151. [PubMed]

29. Thiery JP, Acloque H, Huang RY, Nieto MA (2009) Epithelial-mesenchyma transitions in development and disease. Cell 139: 871-890. [PubMed]

30. Delorme B, Ringe J, Gallay N, Le Vern Y, Kerboeuf D, et al. (2008) Specific plasma membrane protein phenotype of culture-amplified and native human bone marrow mesenchymal stem cells. Blood 111: 2631-2635. [PubMed]

31. Dominici M, Le Blanc K, Mueller I, Slaper-Cortenbach I, Marini F, et al. (2006) Minimal criteria for defining multipotent mesenchymal stromal cells. The International Society for Cellular Therapy position statement. Cytotherapy 8 : 315-7. [PubMed]

32. Pontikoglou C, Delorme B, Charbord $P$ (2008) Human bone marrow native mesenchymal stem cells. Regen Med 3: 731-741. [PubMed]

33. Russell KC, Phinney DG, Lacey MR, Barrilleaux BL, Meyertholen KE, et al. (2010) In vitro high-capacity assay to quantify the clonal heterogeneity in trilineage potential of mesenchymal stem cells reveals a complex hierarchy of lineage commitment. Stem Cells 28: 788-798. [PubMed]

34. Muraglia A, Cancedda R, Quarto R (2000) Clonal mesenchymal progenitors from human bone marrow differentiate in vitro according to a hierarchical model. J Cell Sci 113: 1161-1166. [PubMed]

35. Kyrmizi I, Hatzis P, Katrakili N, Tronche F, Gonzalez FJ, et al. (2006) Plasticity and expanding complexity of the hepatic transcription factor network during liver development. Genes Dev 20: 2293-2305. [PubMed]

36. Lee CS, Friedman JR, Fulmer JT, Kaestner KH (2005) The initiation of live development is dependent on Foxa transcription factors. Nature 435: 944-947. [PubMed]

37. Peschanski M, Defer G, N'Guyen JP, Ricolfi F, Monfort JC, et al. (1994) Bilateral motor improvement and alteration of L-dopa effect in two patients with Parkinson's disease following intrastriatal transplantation of foetal ventra mesencephalon. Brain 117: 487-499. [PubMed]

38. Vacanti JP, Kulig KM (2014) Liver cell therapy and tissue engineering fo transplantation. Seminars in Pediatric Surgery 23: 150-155. [PubMed] 
Citation: Zhang W, Hamidouche Z, Pourcher G, Gribova V, Haghighi F, et al. (2014) A Population of Human Mesenchymal Stem Cells Specific to the Fetal Liver Development. J Stem Cell Res Ther 4: 238. doi:10.4172/2157-7633.1000238

Page 9 of 9

39. Park SR, Oreffo RO, Triffitt JT (1999) Interconversion potential of cloned human marrow adipocytes in vitro. Bone 24: 549-554. [PubMed]
40. Song L, Tuan RS (2004) Transdifferentiation potential of human mesenchymal stem cells derived from bone marrow. FASEB J 18: 980-982. [PubMed] 